\title{
Água potável em São José dos Quatro Marcos, Brasil: percepções da população.
}

Agua potable en São José dos Quatro Marcos, Brasil: percepciones de la población.

Drinking water in São José dos Quatro Marcos, Brazil: perceptions of the population.

Alfredo Zenén Domínguez González/Universidad Estatal de Mato Grosso, Brasil/alfredozdg@unemat.br

Cleia Dias Vieira/Escola Municipal Vereador Evilasio Vasconcelos, Brasil/cleia geografia@gmail.com

Recibido: 22/6/2020 Aceptado: 29/7/2020 Publicado: 30/12/2020

\section{RESUMO}

Tendo em vista a situação diagnosticada no Plano Municipal de Saneamento Básico da cidade mato-grossense de São José dos Quatro Marcos, o presente estudo visou identificar a percepção da população sobre o fornecimento e utilização domiciliar da água para consumo humano nessa cidade, com base na aplicação de um questionário a 419 responsáveis de domicilios distribuídos em diversos bairros. Os resultados evidenciaram que existem percepções negativas da população sobre o tratamento, distribuição e qualidade da água fornecida pela rede pública, estimulando o uso de fontes alternativas, mesmo com uma baixa cobertura de esgotamento sanitário. Paralelamente, percebem que a intermitência no fornecimento de água advém da falta de investimento público no sistema de abastecimento, e as medidas que propuseram mostram desconhecimento da realidade da cidade e das possibilidades de reúso da água. Conclui-se que, além de investir no sistema de abastecimento, o poder público deve conscientizar à população sobre o uso eficiente e o reúso da água.

Palavras chave: abastecimento, percepção social, qualidade da água, reúso, uso

\section{RESUMEN}

Teniendo en cuenta la situación diagnosticada en el Plan Municipal de Saneamiento Básico de la ciudad mato-grossense de São José dos Quatro Marcos, este estudio buscó identificar las percepciones de la población sobre el abastecimiento y utilización domiciliar del agua para consumo humano en la ciudad, a partir de la aplicación de un cuestionario a 419 responsables de domicilios distribuidos en diversos barrios. Los resultados obtenidos indicaron que los problemas relacionados con los servicios de saneamiento básico, especialmente el de abastecimiento de agua potable, influenciaron en el surgimiento de percepciones negativas 
de la población sobre el tratamiento, distribución y calidad del agua ofrecida a través de la red pública, estimulando el uso de fuentes alternativas, aun con la baja cobertura de drenaje sanitario existente. Paralelamente, asocian la intermitencia en el abastecimiento de agua a la falta de inversiones en el sistema de abastecimiento, y las medidas que propusieron muestran desconocimiento sobre la realidad de la ciudad y sobre sus posibilidades de reutilizar el agua.

Palabras clave: abastecimiento, calidad del agua, percepción social, reutilización, uso

\section{ABSTRACT}

Taking into account the situation diagnosed in the Municipal Basic Sanitation Plan of the Mato Grosso city of São José dos Quatro Marcos, this study sought to identify the population's perceptions about the supply and household use of water for human consumption in the city, from the application of a questionnaire to 419 heads of homes distributed in various neighborhoods. The results obtained indicated that the problems related to basic sanitation services, especially the supply of drinking water, influenced the emergence of negative perceptions of the population about the treatment, distribution and quality of the water offered through the public network. stimulating the use of alternative sources, even with the low existing sanitary drainage coverage. At the same time, they associate the intermittency in the water supply with the lack of investment in the supply system, and the measures they proposed show ignorance about the reality of the city and about its possibilities of reusing water.

Keywords: social perception, supply, reuse, use, water quality

\section{INTRODUÇÃO}

Nas últimas décadas, fatores como o crescimento demográfico, a diversificação dos usos da água, e a crescente deterioração do meio ambiente, tem comprometido a quantidade e qualidade da água a escala planetária (Martirani e Peres, 2016). Muitos países e regiões enfrentam uma crise devido à falta de fornecimento de água potável (de qualidade e com preço acessível) e de serviços de saneamento básico, acompanhado da elevada incidência de doenças vinculadas à deterioração da qualidade da água (Marinoski, 2007, apud Favretto et al., 2016).

Segundo o Relatório sobre o Desenvolvimento dos Recursos hídricos no Mundo da Organização das Nações Unidas (2016) essa crise se acentua quando, além da indisponibilidade física, existem problemas de infraestrutura para produzir água potável e as instituições não cumprem suas obrigações no sentido de fornecer água com qualidade e de forma equitativa. Surge então uma competição entre usos e usuários que tem gerado diversos conflitos devido à incompatibilidade entre a demanda e a suas disponibilidades nas bacias hidrográficas e os aquíferos subterrâneos (Bordalo, 2017).

No caso do Brasil, os seus recursos hídricos estão desigualmente distribuídos, tanto no espaço geográfico quanto entre as classes sociais (Francisco, 2004). Paralelamente, a população se concentra em regiões onde a oferta de água é desfavorável e o cenário para o ano de 2030 mostra um incremento de 
21 milhões de pessoas nas cidades, ou seja, $11.7 \%$ a mais do que em 2017, como destacado pela Agencia Nacional da Água do Brasil (2019). Além disto, o rápido crescimento urbano, a insuficiência de sistemas de saneamento básico e o risco de escassez de água e energia devido à deterioração dos recursoshídricos, geram vulnerabilidades nas cidades, algo admitido pelo Painel Brasileiro de Mudanças Climáticas (Ribeiro e Souza, 2016). A Política Nacional de Saneamento do Brasil estabelece que a cidade disponibilize serviços de Águas Urbanas compreendendo: - abastecimento de água de qualidade (incluindo a conservação dos mananciais); a coleta, tratamento e disposição adequados do esgoto sanitário; um sistema de drenagem das águas pluviais; a coleta e disposição dos resíduos sólidos urbanos e a limpeza das ruas (Tucci, 2010). De igual forma, é preciso valorizar o reuso da água residuária advinda de residências, indústrias, instalações agropecuárias e outras fontes, para diversas finalidades.

No interior do Brasil, o uso desordenado das bacias hidrográficas foi influenciado pelos programas governamentais de ocupação da região Centro-Oeste (Bezerra e Cleps Júnior, 2004), atingindo o setor sudoeste do atual Estado de Mato Grosso, onde o desmatamento e as queimadas para implantar atividades agropecuárias, bem como a criação de espaços urbanos, alteraram a qualidade das águas superficiais e subterrâneas (Schiavinato e Gonzalez, 2019).

No caso do município de São José dos Quatro Marcos, onde a maioria dos seus 18998 habitantes está concentrada na sede municipal (Segundo o Censo do Instituto Brasileiro de Geografia e Estatística (IBGE) (2010), o ranking do Sistema Nacional de Informações sobre Saneamento (SNIS) (Ministério do Desenvolvimento Regional, 2018) destacava que apenas $75.94 \%$ dos domicílios são abastecidos pela rede pública de distribuição de água tratada (no país é de $82.9 \%$ ). Além disso, o Plano Municipal de Saneamento Básico (2014) relata que somente $9.3 \%$ dos domicílios possuem ligações à rede de esgoto ou pluvial, o que coloca o município no lugar 1185 dentre os municípios de pequeno e médio porte. Esta realidade explica a necessidade de conhecer a percepção dos moradores sobre os serviços de saneamento básico da cidade, tendo em vista que o significado dado ao meio ambiente (com base nas experiências pessoais, relações sociais e cultura), orientam as atitudes, escolhas e comportamentos individuais (Souza, 2015), que diferem entre os indivíduos conforme variáveis como idade, sexo e local de moradia, como apontado por OlmosMartínez et al. (2016). Nesta comunicação se apresentam os resultados de um estudo que objetivou identificar a percepção da população residente na cidade de São José dos Quatro Marcos sobre o fornecimento e utilização domiciliar da água potável.

\section{MATERIAIS E MÉTODOS}

A área de estudo corresponde ao perímetro urbano dessa cidade (figura 1), sede do município homônimo localizado na região de planejamento sudoeste de Mato Grosso (Governo do Estado de Mato Grosso, 2017). Esse perímetro urbano ocupa $10 \mathrm{~km}^{2}$ e se encontra a uma altitude de $230 \mathrm{~m}$. 
Figura 1. Localização da cidade de São José dos Quatro Marcos.

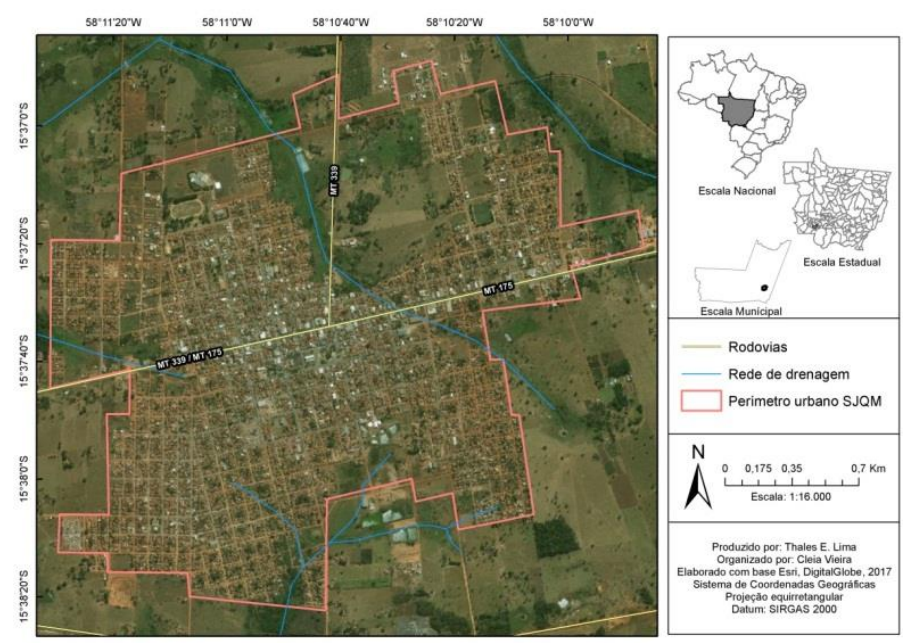

Fonte: Elaborado com base em Google Earth (2018).

O estudo foi executado entre os meses de fevereiro e outubro de 2018, em três etapas: a primeira, de gabinete, abrangeu a revisão bibliográfica sobre o tema e a consulta de documentos de órgãos públicos como o Instituto Brasileiro de Geografia e Estatística e a Secretaria de Planejamento do Estado de Mato.

Grosso-SEPLAN, Sistema Nacional de Informações sobre Saneamento e Plano Municipal de Saneamento Básico (PMSB), para caracterizar a área de estudo. Finalmente, elaborou-se um questionário com base em Sousa (2013) para conhecer as percepções dos usuários sobre o fornecimento e utilização domiciliar da água potável na cidade. O mesmo contém 30 questões, agrupadas nos seguintes blocos para a sua análise: (1) dados pessoais e familiares; (2) percepções sobre os serviços de saneamento básico na cidade, em especial o de água potável e (3) dados sobre a utilização domiciliar da água.

$\mathrm{Na}$ etapa de campo foram realizadas observações nos bairros para verificar a situação da infraestrutura de serviços básicos neles e, a seguir, foi aplicado o questionário aos responsáveis de domicílios desses bairros. A seleção dos bairros foi realizada com base em dois critérios: situação topográfica, para incluir aqueles situados nas partes mais altas da cidade, e o seu tamanho, para incluir os 10 maiores bairros da cidade. Nos bairros, a escolha dos domicílios a amostrar realizou-se de forma aleatória. Em cada caso foi solicitado aos entrevistados a sua adesão ao termo de consentimento livre e esclarecido. Após realizar o pré-teste correspondente, foram distribuídos 700 questionários tanto nas moradias como entre funcionários de instalações da rede de comercio e serviços da cidade. Nos 470 questionários respondidos e devolvidos foram verificados os dados faltantes ou preenchidos erradamente, eliminando aqueles onde essas faltas ou erros fossem superiores a $10 \%$ do total de questões. Dessa forma, foram descartados 51 questionários, ficando a amostra constituída por 419 responsáveis de famílias. 
$\mathrm{Na}$ terceira etapa realizou-se a análise quali-quantitativa dos dados coletados, agrupando-os em categorias de respostas para serem tabulados e processados no software Excel, utilizando gráficos para a sua melhor interpretação. Finalmente se fez a discussão desses dados, relacionando-os com outros resultados de pesquisas voltadas à identificação das percepções da população sobre o tema estudado.territorio.

\section{RESULTADOS E DISCUSSÃO}

Baseado no fato de que existe uma relação entre as variáveis do perfil socioeconômico e a percepção ambiental dos entrevistados, como elencado por Brotto et. al. (2017), buscou-se traçar esse perfil. Na primeira pergunta, relacionada com o sexo, verificouse que na amostra estudada há um predomínio das mulheres ( $66.6 \%$ do total) sobre os homens (33.4\%). Quanto à idade, predominaram as pessoas com 31 a 40 anos (41.52\% da amostra), seguidos daqueles com 41 a 50 años (29.35\%). Nota-se que em apenas 74 pessoas a idade foi superior a 50 anos (figura 2).

Figura 2. Faixas etárias das pessoas amostradas na cidade de São José dos Quatro Marcos.

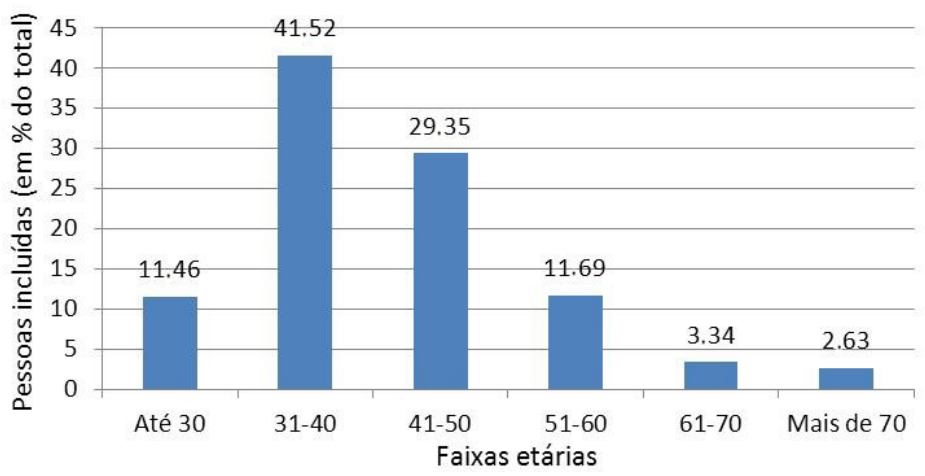

Fonte: Elaboração própria.

O estado civil predominante na amostra foi de pessoas casadas (74\% do total), com escassa proporção de solteiras (11.9\%), divorciadas (8.6\%) e viúvas (5.5\%). Em relação ao número de residentes nos domicílios, predominaram aqueles com 3 a 4 moradores (66.1\%). Porém, em $20.8 \%$ deles mora entre 5 e 6 pessoas (ou mais, em casos isolados), o que pode estar relacionado à falta de recursos para comprar ou alugar casa, ou à quantidade de filhos, pois apenas recentemente começou a diminuir no Brasil o número de filhos por família (Leone et al., 2010). Finalmente, em $13.1 \%$ dos domicílios residem entre uma e duas pessoas. A correlação deste dado com o estado civil mostrou que geralmente se trata de pessoas solteiras, divorciadas ou viúvas.

No que se refere à escolaridade, o $37.9 \%$ das pessoas amostradas concluíram o ensino fundamental ou o ensino médio, enquanto o $31.7 \%$ delas se formou (ou estão estudando) em alguma instituição de ensino superior. Porém, ainda $26.3 \%$ da amostra declararam não ter concluído o ensino fundamental ou o ensino médio, e outro $4.1 \%$ informou que são analfabetos (figura 3). 
Figura 3. Nível de escolaridade dos responsáveis de familias pesquisadas em São José dos Quatro Marcos.

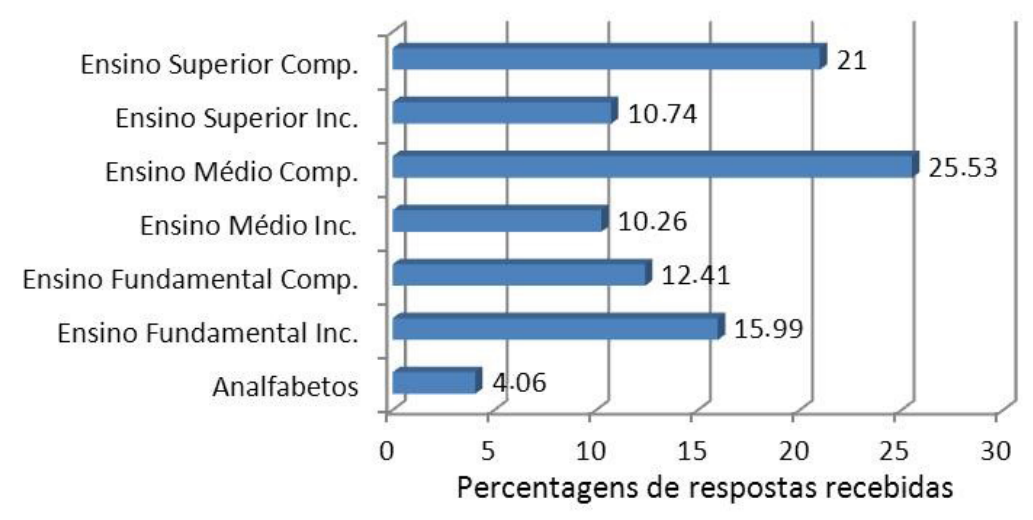

Fonte: Elaboração própria.

Tendo em vista que as experiências advindas do tempo de residência no bairro reforçam a percepção das pessoas sobre o tema estudado, foi perguntado sobre este aspecto, verificando-se que uma parte considerável da população pesquisada (44 \%) mora há mais de 10 anos nele, e em outro $20 \%$ esse tempo é de mais de seis anos. Isso tem Ihes permitido vivenciar por mais tempo a problemática do funcionamento dos serviços de saneamento básico que recebem (especialmente esgotamento sanitário, coleta de resíduos sólidos e fornecimento de água potável) - que garante maior confiabilidade das respostas oferecidas sobre esse aspecto de interesse para a presente pesquisa.

Em relação à percepção sobre os serviços básicos, confirmou-se que as fossas constituem a alternativa mais viável de esgotamento sanitário, pois apenas 32 domicílios (7.6\% do total pesquisado) possuem conexão à rede de esgoto, mostrando uma situação típica da cidade estudada, segundo destacado no PMSB
(2014). Dessa forma, $52.3 \%$ das famílias utilizam fossa séptica para a drenagem sanitária, mesmo que o caráter «séptico» das fossas muitas vezes não é real, pois elas são construídas sem rebocar os tijolos, visando facilitar a infiltração do liquido do esgoto e, desta forma, diminuir a frequência de contratação do serviço de limpeza da fossa. Entretanto, $40.1 \%$ utiliza fossa rudimentar. Em contraposição, 99\% dessas residências recebem o serviço de coleta de resíduos sólidos regularmente, sendo que nas restantes eles são queimados, como declararam os entrevistados.

No tocante à água potável, a primeira questão visava conhecer a sua origem nos domicílios. Nas respostas confirmou-se que 92.1\% deles se abastecem da rede pública de distribuição. Porém, em 3.6\% dos casos a água advém da rede e de poços tubulares conectados a ela. As restantes famílias estudadas se abastecem exclusivamente de poço tubular (3.1\%) ou de poço comum (1.2\%). Nestes casos, consumir agua não tratada gera risco 
para a saúde, como afirmam Medeiros et al. (2016). Paralelamente, o consumo de água de poços tubulares contradiz o estabelecido pela Portaria No 2914/2011 do Ministério da Saúde do Brasil (2011), no sentido de que toda a água para consumo humano coletivo, que seja distribuída coletivamente através de sistema de abastecimento outra alternativa, deverá possuir um padrão de potabilidade que não afete a saúde do consumidor. Além disso, a água dos poços tubulares é misturada nas tubulações com água tratada, intensificando o risco à saúde.

No tocante à frequência de chegada da água às residências durante o dia, duas respostas foram as mais recorrentes: o $43.9 \%$ das pessoas afirmaram que estão acostumados à falta da água em qualquer momento do dia, enquanto outro $34.8 \%$ delas respondeu que a água da rede chega apenas no período noturno. Um estudo da percepção dos usuários no Estado de Pará, realizado por Maia et al. (2015) registrou resultados similares sobre intermitências no fornecimento de água potável.

Essa intermitência atinge especialmente às residências dos bairros situados em posição topográfica alta, devido à incidência de fatores como: vazamentos nas tubulações por serem muito antigas e variações no diâmetro das mesmas, que afetam a pressão: quando ela é baixa, a água não chega às caixas d'água; além disto, a água liberada para distribuição na Estação de Tratamento de Água circula inicialmente por bairros mais baixos. Por isso, quando solicitada uma avaliação do abastecimento de água no bairro, o $78.3 \%$ das pessoas o consideram ótimo ou bom e o resto Ruim ou Péssimo; neste último caso são moradores de bairros altos como Jardim Peruche e Morada do Sol.

A seguir questionou-se sobre a sazonalidade da intermitência. Para os que admitiram esse fato (38.2\% da amostra), as opiniões sobre a época do ano em que a água costuma faltar com mais frequência nas residências são diversas; porém, predominam os que afirmaram que ocorre no inverno, coincidindo com a época da seca, e os que disseram que isso acontece o ano todo (figura 4). Quando cruzadas as respostas a esta questão com a posição topográfica do bairro onde o domicílio amostrado se localiza, confirmou-se que em todos os casos em que a água falta o ano todo, o domicílio está em um bairro alto.

Figura 4. Ocorrências de falta de água ao longo do ano nas residências da cidade de São José dos Quatro Marcos.

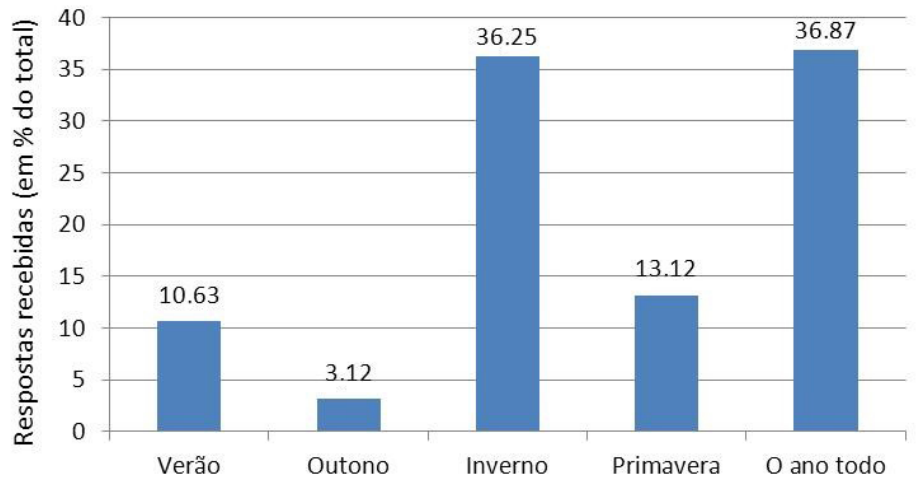

Fonte: Elaboração própria. 
Sobreas possíveis causas dessa intermitência, o $48.2 \%$ das pessoas amostradas atribui o problema à falta de investimentos no sistema de abastecimento, ou a consequências desse fato como: antiguidade das canalizações (respondida por $37.9 \%$ da amostra), perdas na distribuição (13.4\%) e falta de pressão nas tubulações, que afeta o fornecimento nos bairros altos, como reconhecido por $4.5 \%$ das pessoas amostradas (figura 5). Chamam a atenção outras razões colocadas para explicar a falta de água: desperdício de água nos domicílios (27.7\% das respostas); diminuição do volume anual de precipitações na região (11.5\%); falta de proteção das áreas de nascentes que abastecem o córrego Corgão, que compromete a qualidade da água bruta captada para abastecer a cidade (6.9\%); e falta de pagamento das contas pelos usuários por causa da irregular mensuração do consumo (2.5\%).

Figura 5. Possíveis causas da falta de água nos domicílios da cidade de São José dos Quatro Marcos.

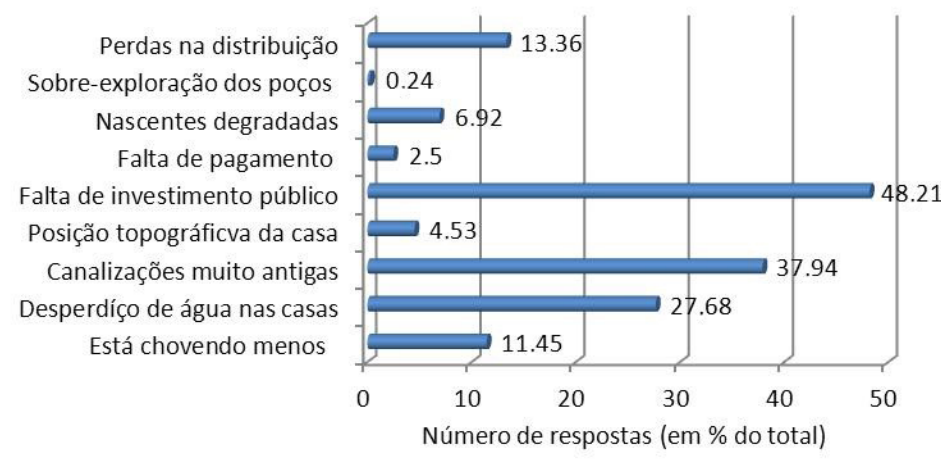

Fonte: Elaboração própria.

Buscando complementar essas respostas questionou-se, a seguir, como se poderia resolver o problema da falta de água. Nas respostas (figura 6), a maioria propôs construir outra estação de tratamento de agua, ou manter ligadas por mais tempo as bombas na atual estação, evidenciando desconhecimento sobre o fato de as bombas funcionarem atualmente durante as 24 horas para tentar satisfazer a demanda. Outras propostas sugeridas (como distribuir a água de forma mais equitativa entre os bairros e aumentar o volume de água captada diariamente das fontes) indicaram desconhecimento da real situação do sistema de abastecimento de agua potável da cidade.

Outra questão buscava conhecer a opinião sobre a qualidade da água potável fornecida à população. Nas respostas, a grande maioria (77.3\%) mostrou insatisfação, o que poderia estar relacionado com o odor e sabor desagradáveis advindos da quantidade excessiva de cloro contido na água devido à falta de aparelho de dosagem na estação de tratamento. Dessa forma, essa rejeição levou muitas pessoas a optar por água obtida de fontes que podem estar poluídas, sem saber do risco que isto implica para a sua saúde (Sousa, 2013). 
Figura 6. Propostas para resolver os problemas da água potável na cidade estudada.

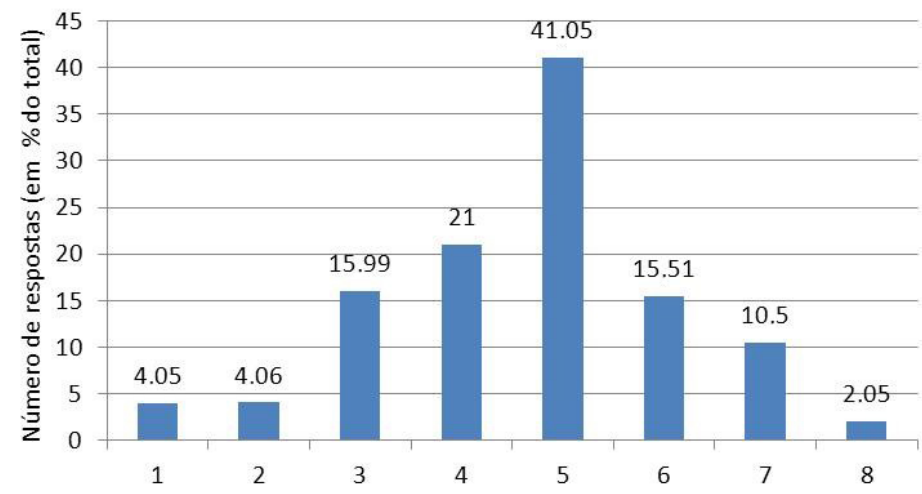

Nota: 1- Aumentar o volume de água captada; 2-Diversificar as fontes de abastecimento; 3- Maior equidade na distribuição entre bairros; 4- Maior tempo de bombeio na estação de tratamento; 5- Construir outra estação; 6- Criar incentivos ao baixo consumo; 7- Recuperar áreas de nascentes do córrego Corgão; 8- Privatizar o Departamento de Agua e Esgoto.

Fonte: Elaboração própria.

Este resultado de rejeição pela água da rede de distribuição foi confirmado nas respostas à seguinte questão: Os residentes do domicílio costumam beber água da torneira? Neste caso, o $87.1 \%$ das pessoas negaram o fato, argumentando que buscam água em sítios próximos à cidade, ou que compram água mineral como alternativa. Quando analisada a relação entre estes últimos e a escolaridade, confirmou-se que os que compram água são sujeitos com um nível de escolaridade mais elevado.

Buscando conhecer os efeitos na saúde do consumo de água não tratada, foi perguntado, a seguir, se algum dos moradores do domicilio tem sofrido doenças advindas do consumo da água obtida de poços, sendo que só o $10.7 \%$ da amostra reconheceram doenças como diarreia, amebíase e disenteria bacteriana.

Quando questionados se tem realizado algum tipo de análise da qualidade da água de consumo, quase todos (97.4\%) negaram o fato (os que o admitiram disseram que isso foi feito na época em que a família mudou-se para a cidade). E quando indagados sobre o tratamento dessa água, apenas $1.7 \%$ das pessoas respondeu afirmativamente, destacando a filtração (88.2\% desses casos). Não foi avaliado o tipo de filtro utilizado e nem o tipo de limpeza que realizam e a sua frequência.

O último bloco de perguntas buscava obter dados sobre a utilização domiciliar da água. Na primeira questão perguntou-se sobre a capacidade total de armazenamento domiciliar de água. Foi corroborado que todas as residências dispõem de caixa d'água, sendo esta a única alternativa de armazenamento em $92.1 \%$ dos casos, com capacidades variadas: em $12.4 \%$ delas a caixa tem capacidade para 1000 L de água, em $47.9 \%$ para 500 e em 39.6\% apenas para 250. Porém, apenas o $7.9 \%$ dessas residências utilizam a cisterna como alternativa complementar de armazenamento de água. Em relação à 
limpeza da caixa d'água, todos afirmaram que realizam a mesma. Entretanto, a frequência da limpeza variou entre eles, predominando a semestral (42.1\% dos casos), seguida dos domicílios onde não existe uma frequência de limpeza (34\%), pois neles a caixa d'água só sofre limpeza quando "está suja». Salientase que um resultado similar foi obtido por
Garcia (2018) em estudo sobre a percepção pública e qualidade da água distribuída na cidade brasileira de Florianópolis.

Outra questão visava conhecer as atividades que mais água demanda diariamente nas casas. As respostas aparecem na figura 7 , a seguir.

Figura 7. Principais usos domésticos da água na cidade de São José dos Quatro Marcos.

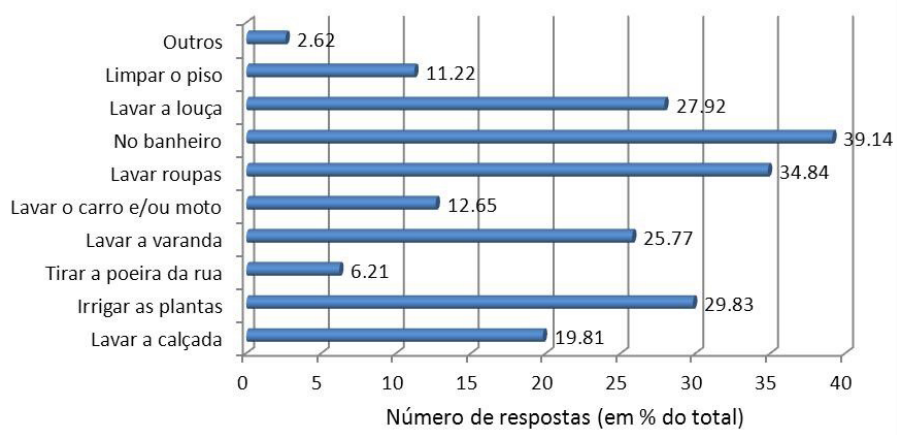

Fonte: Elaboração própria.

Quando ordenadas essas atividades pelo número de respostas (figura 7), verificou-se que as maiores percentuais corresponderam ao banheiro (39.1\%), lavagem de roupas (34.8\%), aguar as plantas de jardins e hortas caseiras (29.8\%), lavar a louça (27.9\%), lavar as varandas (25.8\%), e lavar a calçada (19.8\%). Note-se que o banheiro constitui o principal espaço de consumo identificado, sendo que, segundo Mota et al. (2006) o desperdício de água nos chuveiros pode chegar à metade de toda água consumida por uma casa. Resultados similares tem sido encontrados tanto no Brasil (como é o caso do estudo da percepção dos moradores sobre o consumo da água na cidade brasileira de Curimatá, realizado por Moraes et al. 2018) como em outros países (por exemplo, Molina et al. 2018 na pesquisa sobre o consumo de água em domicílios da cidade de Cuenca, Equador).

Os resultados mostrados na figura 7 indicam a necessidade de estabelecer uma política de reúso domiciliar da água, especialmente as águas cinza claras procedentes de banheiros, chuveiros, lavatórios e máquinas de lavar roupa. Esta necessidade é demonstrada quando analisadas as respostas à seguinte questão, relacionada com o conhecimento, ou não, da possibilidade de reuso da água: apenas $32.7 \%$ das pessoas amostradas admitiram conhecer que a água utilizada no domicilio pode ser objeto de reuso.

Para este grupo, as possíveis alternativas de reuso seriam: a utilização da água residuária da lavagem de roupa para outras finalidades 
como: lavar a varanda e a calçada, apagar poeira da rua, lavar o carro ou moto, e para a descarga do banheiro (39.1\% das pessoas amostradas colocaram ao menos uma dessas alternativas); reutilizar a água da pia para irrigar plantações (13.1\%); e fazer reúso da água de limpar o piso na irrigação do jardim (42.3\%). Algumas destas propostas coincidem com aquelas registradas por Grande et al. (2016) em estudo sobre a percepção de usuários sobre os impactos do racionamento de água na cidade brasileira de Campina Grande, no estado da Paraíba.

Também existe a alternativa de fomentar o reuso municipal da água em atividades como: proteção contra incêndios; controle de poeira em estradas; construção civil; lavagem de ruas e dos ónibus da Prefeitura; e irrigação de áreas verdes. Esta última alternativa de reutilização é a mais comum nos municípios, segundo Kubler et al. (2015), onde a água é usada- prévia desinfeção com cloro ou raios ultravioletas- em canteiros de estradas, gramados residenciais, campos de golfe e irrigação de parques. No caso dos esgotos domésticos, quando devidamente tratados com as tecnologias disponíveis, podem-se consumir como água potável (como explicitado por Hespanhol, 2015) ou receber um tratamento ecológico simples que permita o reuso, evitando as afetações na qualidade da água advindas do despejo de esgotos sanitários nos corpos d'água, como apontara Barbosa (2012).

A última pergunta buscava conhecer a opinião das pessoas sobre a política de pagamento da água na cidade, sendo que as opções oferecidas eram: ótima, boa, ou ruim. Nas respostas, a grande maioria das pessoas $(78.5 \%)$ a considerou como Boa e outro $4.5 \%$ achou que é Ótima. Ou seja, $83.1 \%$ das pessoas pesquisadas aprova essa política (o que pode estar relacionado, em alguns casos, com o fato de que quem não paga o serviço, não é punido com o corte do fornecimento). Os que consideraram que essa politica é ruim (16.9\% da amostra) basearam-se em dois aspectos: preço do serviço e gerenciamento do sistema de abastecimento de água potável, como explicitado a seguir:

Em relação ao preço, em $40 \%$ dos bairros estudados: Centro, Jardim das Oliveiras, Bela Vista, J. Popular, J. Peruche e J. Rondon, as pessoas criticaram o preço da agua e o uso de uma taxa, pois quem consume pouca água deve pagar o mesmo valor que os que consumem muita, sendo que o correto seria pagar pela quantidade consumida e não pela taxa. Nas respostas a esta pergunta também foi citado o gerenciamento do abastecimento de água potável, sendo que em $40 \%$ dos bairros: Bela Vista, Centro, J. Peruche, Morada do Sol, J. das Oliveiras e J. Popular; existem critérios negativos, com argumentos como: falta de controle sobre o pagamento; não supressão do fornecimento a aqueles que não pagam pelo serviço; e ausência de uma campanha para que todos paguem, com desconto, um valor justo.

\section{CONCLUSÕES E RECOMENDAÇÕES}

$O$ estudo realizado permitiu constatar uma baixa cobertura de esgotamento sanitário e diversos problemas no sistema de abastecimento de água potável da cidade de São José dos Quatro Marcos, 
que influenciam tanto no uso de fontes alternativas para obter água, como na percepção negativa generalizada da população sobre o tratamento, distribuição e qualidade da água fornecida através da rede pública. Ao mesmo tempo, percebem que a intermitência no fornecimento advém da falta de investimento público no sistema de abastecimento, sendo que as medidas que propõem para enfrentar os seus efeitos indicam um desconhecimento da realidade da cidade, bem como das possibilidades de reuso da água utilizada. Recomendase ao poder público municipal, informar à população sobre a atual situação da oferta de água potável na cidade, corrigir as insuficiências identificadas no sistema de distribuição e estimular a redução da demanda e o reuso da água pelos usuários.

\section{REFERENCIAS BIBLIOGRÁFICAS}

Agencia Nacional de Águas. (2019). Manual de Usos Consuntivos da Água no Brasil. Agencia Nacional de Água. https://bit.ly/3oWE89g

Barbosa, M.S. (2012). A percepção de agricultores familiares e formuladores de políticas - o reúso da água no Semiárido baiano [Tese de doutorado, Universidade Federal da Baia]. Repositório Institucional UFBA. https://bit.ly/3hjzyyK

Bezerra, M.C., e Cleps, J. (2004). O Desenvolvimento Agrícola da Região Centro-Oeste e as Transformações no Espaço Agrário do Estado de Goiás. Caminhos de Geografia, 5(12), 29-49. https://bit.ly/3mQ4Lew

Bordalo, A.L. (2017). Novos olhares da crise hídrica mundial. Em E. Salinas, C.A. Di Mauro y E.C. Moretti, (Orgs.), Água, recurso hídrico: bem social transformado em mercadoria (pp. 1634). Editora Associação Amigos da Natureza da Alta Paulista. https://bit.ly/3jUOWTD

Brotto, D.S., Dias, G.T., Pereira, J.S., e Agarez, V.L.V. (2017). Percepção dos cidadãos do município do Rio de Janeiro quanto à responsabilidade pela situação hídrica atual. Revista Brasileira de Educação Ambiental, 12(1), 85-96. https://doi.org/10.34024/revbea.2017.v12.2277

Favretto, C.R., Schumann, C., Dall'agnol, A.L.B., Nazari, M.T., Araújo, M.M.F., e Quadro, M.S. (2016, julho-agosto.). Análise do sistema de abastecimento de água do município de Arroio do Padre/RS. Anais do XIV ENEEAmb, Brasília-DF, Brasil. https://bit.ly/3jWO9Qh

Francisco, C.N. (2004). Subsídios à gestão sustentável dos recursos hídricos no âmbito municipal: o caso de Angra dos Reis [Tese de doutorado, Universidade Federal Fluminense]. Repositório Institucional UFF. https://bit.ly/3aKdTOX

Garcia, A.T. (2018). Percepção pública e qualidade da água distribuída em Florianópolis, SC: avaliação e proposição de alternativas de tratamento [Tese de doutorado, Universidade Federal de Santa Catarina]. Repositório Institucional UFSC. https://bit.ly/325Cg4v 
Governo do Estado de Mato Grosso. (2017). Regiões de planejamento de Mato Grosso 2017. Secretaria de Estado de Planejamento-SEPLAN. https://bit.ly/329QfX2

Grande, M.H., Galvão, C., Miranda, I.B., e Sobrinho, D.G. (2016). A percepção de usuários sobre os impactos do racionamento de água em suas rotinas domiciliares. Ambiente \& Sociedade, 19(1), 165-184. https://doi.org/10.1590/1809-4422asoc150155r1v1912016

Hespanhol, I.A. (2015). Inexorabilidade do reúso potável direto. Revista DAE, 63(198), 63-82. https://doi.org/10.4322/dae.2014.141

Instituto Brasileiro de Geografia e Estatística (2010). Censo demográfico 2010. https://censo2010. ibge.gov.br/resultados.html

Kubler, H., Fortin, A., e Molleta, L. (2015). Reúso de Água nas Crises Hídricas e Oportunidades no Brasil. Editora da Associação Brasileira de Engenharia Sanitária e Ambiental. https://bit. Iy/3jWOQLg

Leone, E.T., Maia, A.G., e Baltar, P.E. (2010). Mudanças na composição das famílias e impactos sobre a redução da pobreza no Brasil. Economia e Sociedade, 19(1), 59-77. https://bit. $\underline{\text { ly/3jQUcpD }}$

Maia, D., Fernandes, L.L., e Teixeira, L.G. (2015). Diagnóstico do abastecimento e consumo de água segundo a percepção do usuário em duas áreas residenciais no Estado do Pará. Revista Gestão \& Sustentabilidade Ambiental, 4(2), 105-115. https://bit.ly/3mK7pSI

Martirani, L.A., e Peres, I.K. (2016). Crise hídrica em São Paulo: cobertura jornalística, percepção pública e o direito à informação. Ambiente \& Sociedade, 19(1), 1-20. https://bit. $\underline{\text { ly/3mMgOt6 }}$

Medeiros, A., Lima, M. de O., e Guimarães, R.M. (2016). Avaliação da qualidade da água de consumo por comunidades ribeirinhas em áreas de exposição a poluentes urbanos e industriais nos municípios de Abaetetuba e Barcarena no estado do Pará, Brasil. Ciência \& Saúde Coletiva, 21(3), 695-708. https://doi.org/10.1590/1413-81232015213.26572015

Ministério da Saúde. (2011). Portaria No 2.914. Dispõe sobre os procedimentos de controle e de vigilância da qualidade da água para consumo humano e seu padrão de potabilidade. Brasil.https://bit.ly/2Js2p7w

Ministério do Desenvolvimento Regional. (2018). Diagnostico dos serviços de água e esgoto, 2018. Sistema Nacional de Informações sobre Saneamento-SNIS. https://bit.ly/389bRq8

Molina, E., Quesada, F., Calle, A., Ortiz, J., e Orellana, D. (2018). Consumo sustentable de agua em viviendas de la ciudad de Cuenca. INGENIUS, (20), 28-38. https://bit.ly/2TPVID5 
Moraes, L.A., Sousa Filha, E.M.M., Santos, L.A. dos., França, A.A., Araújo, M.F., e Machado, R.B. (2018). O consumo da água na cidade de Curimatá - PI: percepção dos moradores do entorno da barragem Vereda da Cruz. Revista Brasileira de Geografia Física, 11(01), 150166. https://doi.org/10.26848/rbgf.v11.1.p150-166

Mota, M.B., Manzanares, M.D., e Silva, R.A.L. (2006). Viabilidade de reutilização de água para vasos sanitários. Revista Ciências do Ambiente, 2(2), 24-29. https://bit.ly/3mSoc66

Olmos-Martínez, E., Arizpe-Covarrubias, O., Contreras-Loera, M.R., González-Ávila, M.E., e Casas-Beltrán, D. A. (2016). Opinión pública y percepción sobre la conservación de la Reserva ecológica estatal Estero San José del Cabo y su zona de influencia. Revista de comunicación Vivat Academia, 135, 24-40. https://doi.org/10.15178/va.2016.135.24-40

Organização das Nações Unidas. (2016). Relatório sobre o Desenvolvimento dos Recursos Hídricos no Mundo. Água e Emprego. https://bit.ly/3em9DEU

Plano Municipal de Saneamento Básico. (2014). Diagnóstico Geral dos Serviços de Saneamento Básico. São José dos Quatros Marco (MT), Vol. I. https://bit.ly/3oPUkJL

Ribeiro, S.K., e Santos, A. (Eds.). (2016). Mudanças Climáticas e Cidades. Relatório Especial do Painel Brasileiro de Mudanças Climáticas. https://bit.ly/3ekAjGg

Schiavinato, V.M.S., e Gonzalez, A.Z.D. (2019). Avaliação ambiental de nascentes na sub-bacia hidrográfica do córrego das Pitas-MT, Brasil. Revista Equador, 8(3), 260-278. https:// revistas.ufpi.br/index.php/equador/article/view/9396

Sousa, J.C. (2013). Recursos hídricos: breves considerações sobre o sistema de abastecimento de água no município de Montes Claros/MG e a percepção dos cidadãos em relação ao uso da água. Meio Ambiente e Sustentabilidade, 3(2), 102-119. https://bit.ly/3k3kV2p

Souza, E.P. (2015). Qualidade e percepção do ambiente construído: influência nas características psicofisiológicas dos usuários [Tese de doutorado no publicada, Universidade Estadual de Campinas]. Brasil.

Tucci, C.E.M. (2010). Urbanização e recursos hídricos. Em C.E.de M. Bicudo, J.G. Tundisi y M.C.B. Scheuenstuhl (Orgs.), Águas do Brasil: análises estratégicas. Academia Brasileira de Ciências-Instituto de Botânica. http://www.abc.org.br/IMG/pdf/doc-6820.pdf 